\title{
Antimicrobial Resistance and Human Mobility
}

\author{
Angel N Desai ${ }^{1,2}$ \\ Amir M Mohareb ${ }^{3-6}$ \\ Naomi Hauser (D) \\ Aula Abbara ${ }^{7}$ \\ 'Department of Internal Medicine, \\ Division of Infectious Diseases, \\ University of California Davis Medical \\ Center, Sacramento, CA, USA; ${ }^{2}$ Global \\ Migration Center, University of California \\ Davis, Davis, CA, USA; ${ }^{3}$ Department of \\ Medicine, Harvard Medical School, \\ Boston, MA, USA; ${ }^{4}$ Division of Infectious \\ Diseases, Massachusetts General \\ Hospital, Boston, MA, USA; ${ }^{\text {Medical }}$ \\ Practice Evaluation Center, \\ Massachusetts General Hospital, Boston, \\ MA, USA; ${ }^{6}$ Center for Global Health, \\ Massachusetts General Hospital, Boston, \\ MA, USA; ${ }^{7}$ Department of Infection, \\ Imperial College, London, UK
}

\begin{abstract}
Antimicrobial resistance (AMR) is of increasing global concern. Human mobility is one factor that has recently been associated with AMR, though the extent of its impact has not yet been well established due to the limited availability of rigorous data. This review examines the existing literature regarding various types of human mobility including shortterm travelers, forcibly displaced persons, migrant populations, and their association with global rates of AMR.
\end{abstract}

Keywords: antimicrobial resistance, migrant, refugee, displaced person, traveler, mobility

\section{Background}

Antimicrobial resistance (AMR) is a global problem of increasing importance. In the United States, nearly 3 million antibiotic-resistant infections occur each year and more than 35,000 people die from their complications. ${ }^{1}$ In Europe, AMR is responsible for around 33,000 deaths per year. ${ }^{2}$ In low- and middle-income countries, the true burden and effects of AMR have been more difficult to quantify. Because severe bacterial infections comprise the most common cause of childhood mortality in resource-constrained settings, the effects of AMR may be responsible for even greater life-years lost in these settings. ${ }^{3}$

Increasing global antibiotic use and access to non-prescription antibiotics may partially explain the rising observed burden of AMR. AMR is also associated with increasing non-human uses of antibiotics, particularly for growth promotion and veterinary uses in the agricultural industry. ${ }^{4}$

Human mobility has putatively been suggested to contribute to the spread of AMR internationally. There has been a heightened awareness of this in recent years with respect to the prevalence of infection or colonization with drug-resistant organisms in people who experience short-term international travel, economic migration, and forced displacement from conflict or other disasters. However, the risks of AMR are not shared equally between these different populations. In this article, we review the evidence associated with human mobility and AMR.

\section{Methods}

We searched PubMed for English-language articles published from January 1, 2001, to July 15, 2021, by use of the MeSH terms ["microbial drug resistance" or "antimicrobial stewardship"] and ["emigrants and immigrants" or "refugees" or "transients and migrants" or "travel/ international travel"]. Relevant articles were also identified through searches in the authors' personal files and in Google Scholar. Articles resulting from these searches and relevant references cited in those articles were reviewed.
Department of Internal Medicine, Division of Infectious Diseases, University of California

Davis, Sacramento, CA, USA

Tel +19167340168

Fax + | 25| 333|I5250

Email andesai@ucdavis.edu 


\section{Human Mobility}

Modes and reasons for human mobility are varied and may be characterized in terms of political, economic, and social factors. ${ }^{5}$ Prior to the COVID-19 pandemic, tourism was reported to be one of the fastest growing global economic sectors. ${ }^{6}$ It is estimated that commercial air travel accounts for around 3.5 billion trips annually with $40 \%$ of these international. $^{7} \quad$ The World Tourism Organization (UNWTO) predicts that international tourism will continue to increase and estimates that international tourist arrivals will be 1.8 billion by $2030 .^{6}$ A recent study by Tuite et al noted that countries with increasing fragility scores, a measure of country resiliency and by proxy, the ability to respond to infectious disease threats, correlated to a decrease in outbound travel. ${ }^{7}$ This study also reported an increase in travel between Warning category countries that could increase the impact of communicable diseases including AMR given potential vulnerabilities and poor infrastructures affecting their ability to detect and respond to communicable disease threats. ${ }^{7}$

Another form of mobility refers to migration apart from short-term international travel. The term "migrant" encompasses a diverse group including refugees, asylum seekers, and internally displaced populations. ${ }^{8,9}$ These categories differ from economic migrants who leave their country of origin for employment, education, or familial reunification (Table 1). Approximately 3.5\% of the world population (an estimated 272 million people) are considered international migrants with some leaving their home for economic reasons and others driven from their homes due to conflict, humanitarian disasters and, increasingly, the local effects of climate change. ${ }^{8}$ In 2019 , 50.8 million people were IDPs due to conflict, violence and other disasters. ${ }^{9}$ As such, migration is influenced by social, economic, political and environmental factors both as a driver en route and in the destination country. ${ }^{10}$ It is also important to note that many individuals who are forcibly displaced may also seek economic opportunities in the course of migration.

The last several years have also seen an increase in the number of those who have been forcibly displaced from their homes, particularly from Syria, Afghanistan, and Somalia countries facing protracted conflict and where more than $50 \%$ of current refugees originate. ${ }^{10}$ Though increasing numbers of refugees have found themselves in Europe, the main refugee-hosting countries remain in low- and middle-income countries (LMIC) including Jordan, Lebanon, and Pakistan. ${ }^{10}$

\section{Human Mobility and AMR}

Throughout history, human and animal mobility have contributed to the spread of communicable diseases with the COVID-19 pandemic being a notable example. ${ }^{11}$ The association between increasing human mobility and antimicrobial resistance is complex. Differing modes of mobility have more recently been associated with colonization with and/or transmission of multidrug resistant organisms

Table I Categories of Human Mobility

\begin{tabular}{|c|c|}
\hline Category & Description $^{12,40}$ \\
\hline \multicolumn{2}{|l|}{ Forcibly Displaced Persons } \\
\hline Internally Displaced Person & One who flees within the borders of their own country due to a fear of persecution or violence \\
\hline $\begin{array}{l}\text { Refugee (I95I } \\
\text { Convention) }\end{array}$ & One who flees their country of origin due to a well-founded fear of persecution or violence \\
\hline Asylum-Seeker & $\begin{array}{l}\text { One who has fled their country of origin and seeks international protection against forced return due to a fear of } \\
\text { persecution or violence }\end{array}$ \\
\hline $\begin{array}{l}\text { Economic Migrant } \\
\text { Labor Migrant }\end{array}$ & One seeks to improve their economic, educational, or other opportunities in a new country \\
\hline Environmental Migrant & $\begin{array}{l}\text { One who leaves their residence due to rapid or progressive environmental change forcibly or by choice. There is } \\
\text { no international or legal agreement to define this category }\end{array}$ \\
\hline International Travel & One who travels without seeking resettlement for personal, business, or religious reasons \\
\hline Short-term travel & Intent of travel for personal, business, or religious reasons \\
\hline Visiting Friends or & Intent of travel to visit friends or relatives \\
\hline Relatives (VFR) & Varied health risks between two locations \\
\hline
\end{tabular}


(MDRO). International travel, and particularly short-term international travel for the purpose of tourism or business, may portend different communicable disease risks compared with migration for the purposes of resettlement. In addition, a unique group known as "VFR," or "visiting friends or relatives," may also be associated with varying levels of risk of exposures to communicable diseases and AMR. ${ }^{12}$ Assessing epidemiologic risk, countries of origin and destination, as well as integration with local populations may impact the potential for AMR transmission.

\section{International Travel}

One of the most consistent associations with AMR reported in observational cohort studies relates to shortterm international travelers. MDRO acquisition among short-term travelers has been recognized as a potential contributor to global AMR dissemination, particularly in the setting of multidrug-resistant Enterobacterales (MRE). This includes extended spectrum beta-lactamases (ESBLs) and carbapenem-resistant Enterobacterales (CREs.)

Digestive tract colonization by MREs in travelers, particularly among those traveling from low prevalence to high prevalence settings, is an increasingly recognized epidemiological phenomenon. ${ }^{13-15}$ In one observational cohort study examining adults traveling to Latin America, sub-Saharan Africa, or Asia for between 3 days to 3 months, acquisition of MRE was relatively frequent $(51 \%)$, though carriage was brief (5\% still carried MRE after three months). ${ }^{16}$ Notably, approximately half of the study participants acquired at least $1 \mathrm{MRE}$ during travel, with higher rates of acquisition more commonly associated with travel to Asia, beta-lactam use, diarrhea, and type of travel. Most MRE isolated from stool samples over the course of the study were identified as E.coli (93.3\%), and ESBL production was reported as the primary resistance mechanism $(91.8 \%) .{ }^{16}$ Only $4.7 \%$ of travelers who were followed were still MRE carriers past 3 months after their return, suggesting a relatively limited duration of carriage.

Similarly, a large prospective, multicenter study from the Netherlands reported that of 1847 participants, 34.3\% (633) with negative fecal samples obtained before travel acquired ESBL following international travel. ${ }^{17}$ Risk factors for ESBL colonization included travel to southern Asia, antibiotic use during travel, persistent traveler's diarrhea, and pre-existing chronic bowel disease. ${ }^{17}$ As previously reported, the median duration of colonization was 30 days after travel and $11.3 \%$ (65) of those with evidence of ESBL colonization after travel remained colonized at 12 months. Moreover, mathematical modeling estimated that the probability of transmitting ESBL to another household member in this sample was approximately $12 \%$. A USbased cohort of short-term international travelers demonstrated that while duration of the trip was not associated with risk of acquisition, the highest rates of MDRO were reported in participants traveling to South Asia and Southeast Asia, concordant with other studies. ${ }^{18}$

Another small multicenter observational study also used culture-based protocols to identify CRE and $m c r-$ mediated colistin-resistant Enterobacterales (MCRE) among 412 US travelers. ${ }^{19}$ While no travelers had evidence of CRE or MCRE in fecal samples prior to travel, 2 travelers acquired CREs and 20 acquired MCREs following travel. Notably, none of the participants in this study showed signs or symptoms associated with these bacterial pathogens on or after their return.

A recent meta-analysis investigating acquisition of multidrug-resistant Enterobacterales during international travel demonstrated that travel to Southern Asia and antibiotic use during travel appear to be risk factors for acquisition while traveling. ${ }^{20}$ Of note, CRE acquisition during travel was relatively rare among pooled studies, however the authors highlight that this may be due to underreporting as most included studies did not use culture methods that specifically target CRE. In addition, consumption of high-risk food such as raw food, milk from open containers, and tap water, which is traditionally associated with traveler's diarrhea and subsequent acquisition of MRE, was not found to be a statistically significant risk factor for travelers and $\mathrm{MRE}$, though recall bias may have affected these results.

Methicillin-resistant Staphylococcus aureus (MRSA) is another major global threat because of its widespread prevalence and high mortality. A study of 598 isolates of Staphylococcus aureus collected across sub-Saharan Africa, including both asymptomatic colonization from community sampling and clinical isolates from health-care settings, demonstrated that $54 \%$ were resistant to trimethoprim, 19\% were resistant to trimethoprim-sulfamethoxazole, and 5\% expressed the mecA gene. That same study also analyzed Staphylococcus aureus isolates from 47 returning travelers from sub-Saharan Africa with skin and soft tissue infections, finding that $57 \%$ had infections resistant to trimethoprim and $11 \%$ resistant to trimethoprimsulfamethoxazole. ${ }^{21}$ While many clinicians in high-income countries have access to alternative oral antibiotics, resource 
limitations in many settings in sub-Saharan Africa mean that the rise of MRSA may be accompanied with daunting challenges in preventing patient morbidity and mortality.

Multidrug-resistant enteric pathogens are also of increasing concern among returning travelers. ${ }^{22,23}$ One multicenter study examining 889 travelers presenting with enteric fever reported antibiotic susceptibility data isolated from 143 Salmonella typhi infections and 75 Salmonella paratyphi infections. 65\% (87/133) of Salmonella typhi isolates were resistant to fluoroquinolones, $50 \%(4 / 8)$ to ampicillin, and $8 \%$ to macrolides (4 of 50). ${ }^{24,25}$ All (2/2) Salmonella paratyphi isolates, on the other hand, were non-susceptible to ampicillin, 56\% (40/ 72 ) to fluoroquinolones, and $16 \%(5 / 31)$ to macrolides. $71 \%$ of all travelers in this cohort reported exposure to enteric fever in South Asia.

Despite the mounting evidence that suggests an association between travel and MDRO acquisition, translating the available data to actionable guidelines for health-care providers and facilities remains limited. More research is needed to better understand the risk of transmission from recently returned travelers to others in the hospital setting as well as whether carriage among travelers warrants isolation and precaution guidelines for health-care settings. ${ }^{20}$ Disruptions in international travel due to COVID-19 may be hypothesized to reduce the total number of MDRO acquisition through this route. However, a countervailing factor in AMR control may be in the general rise in broadspectrum antibiotic use related to COVID-19. ${ }^{26,27}$

\section{Migrants and Forcibly Displaced Persons}

The association between AMR and long-term migration and resettlement, including in forcibly displaced persons, appears to be complex. The risk of antibiotic resistance in migrant communities may be lower in certain regions for example, given reduced access to health-care facilities or antibiotics, or increased due to factors associated with transit such as fractured public health infrastructure and infection control policies and programs. ${ }^{28}$ For the purposes of this review, both are discussed in tandem as much of the existing literature discusses these populations interchangeably, though it is important to highlight that the risk of AMR exposure for migrants such as economic or laborrelated migrants are typically different from those of forcibly displaced persons given varied exposures, environments, and vulnerabilities.

A systematic review and meta-analysis of AMR among migrants and refugees in Europe demonstrated the pooled prevalence of AMR carriage or infection, including methicillin-resistant staphylococcus aureus and gram-negative bacteria, was increased (25.4\% across all migrants) among asylum seekers and refugees residing in highmigrant community settings such as transit or detention centers, or camps, though these estimates were limited by significant heterogeneity. ${ }^{28}$ Notably, the data also suggested that antibiotic-resistant organisms are predominately acquired during or following migration, and there was no evidence of onward transmission to surrounding host populations. This suggests that exposure along the migration trajectory as well as perhaps conditions in highmigrant community settings may contribute to acquisition of AMR among these populations.

The rising burden of AMR is of particular concern in countries affected by protracted conflict where AMR policies are not always implemented. ${ }^{29}$ Despite limited data on AMR in Syria, a country that has been in conflict for more than ten years and has seen more than half its pre-war population of 22 million forcibly displaced (5.6 million as refugees), high rates of CRE have been found. ${ }^{30}$ Among refugees, screening programs in destination countries in Europe such as Germany which hosts more than 800,000 Syrian refugees, noted high rates of MRE among refugees. $^{31}$

Rates of MDR-TB are another area of current interest as it pertains to migrants originating from high-prevalence regions. Migrants, and particularly forcibly displaced persons, may be at increased risk for both TB and MDR-TB due to the breakdown of local health systems and exposures during their migration trajectory, such as overcrowding, incarceration, or detention. ${ }^{32}$ These factors can be particularly challenging for appropriate surveillance and treatment, given concerns surrounding legal status. One cross-border outbreak of MDR-TB that affected 29 patients in seven European countries was discovered among migrants arriving from the Horn of Africa or Sudan, with the majority of patients $(76 \%, \mathrm{n}=22)$ reporting spatiotemporal overlap between their routes of transit. ${ }^{33}$ Of note, all isolates obtained for whole genome sequencing from this outbreak revealed a shared tylA N236K mutation and phenotypic resistance to capreomycin. Most of the patients involved in the outbreak noted transit through Libya prior to their arrival into Europe, with some being held by human traffickers or in detention in unsanitary or overcrowded conditions. Following intensive cross-border surveillance efforts, no reports of 
transmission of this strain occurred outside of those involved in the journey to Europe. ${ }^{33}$

Githui et al observed higher levels of drug resistance to antimycobacterial therapy among refugees in three refugee camp complex clinics located in Northeastern Kenya compared to non-refugees. ${ }^{34}$ A large analysis of patients associated with GeoSentinel, a global surveillance network of travel and tropical medicine clinics in 28 countries, similarly demonstrated that most cases of MDR-TB occurred among foreign-born patients, with over half of cases presenting five or more years after immigration. ${ }^{35}$ None of the MDR-TB cases presented in this analysis occurred among tourists or volunteers and only 3 cases were found in business travelers while 1 case was found in a student. Unlike other forms of AMR, the authors concluded that short-term travel was rarely associated with acquisition of MDR-TB, and that additional resources should be allocated towards optimizing TB cases of patients in their home countries. A recent retrospective cohort study of MDR-TB among migrants in Canada also noted that despite increasing cases of MDR tuberculosis among migrants from high MDR tuberculosis burden countries between 1982-2001 and 2002-2019, no cases of multidrug resistant TB were attributable to local transmission. ${ }^{36}$ In general, there has been sparse evidence of spread from migrants to local communities (with transmission occurring within migrant communities due to poor integration) though further research in this area is needed. ${ }^{32}$

While considerable attention has historically been paid to AMR resulting from the resettlement of migrants, including forcibly displaced persons, there is reason to believe that this population in fact contributes a small fraction of AMR dissemination. Thomas et al note that the frequency of AMR carriage appears roughly similar between short-term international travelers and migrants seeking resettlement. ${ }^{37-39}$ However, in the US and Europe, the population of immigrants and forcibly displaced persons is overshadowed by the much larger population of short-term international travelers, and this difference has been growing over the past five decades. Therefore, effective interventions to reduce the spread of AMR will likely need to be implemented at the interface of international air travel. Interventions to reduce the burden of AMR among migrants seeking long-term resettlement are important but must be framed and communicated in a manner that does not enhance the already high level of stigmatization of this vulnerable population. ${ }^{37}$

\section{Conclusion}

AMR continues to pose one of the most important contemporary challenges to global public health. Human mobility is considered to be an important contributor to AMR, though the current literature suggests that these risks may vary depending on mode and characteristics associated with transit. Several epidemiological studies have illustrated that short-term international travel may be a risk factor for AMR, particularly in relation to MRE, but the state of the science at present has been limited to characterizing the prevalence and duration of digestive tract colonization. Conversely, AMR may affect migrant populations including those that have been forcibly displaced through endemicity in their country of origin, crowded and unsanitary conditions during transit, and failing health infrastructures due to conflict or humanitarian crises. Health-care practitioners should consider these factors while evaluating their patients without further stigmatizing vulnerable communities.

\section{Author Contributions}

All authors made substantial contributions to conception and design, acquisition of data and contributed to analysis and interpretation; took part in drafting the article or revising it critically for important intellectual content; agreed to submit to the current journal; gave final approval of the version to be published; and agree to be accountable for all aspects of the work.

\section{Funding}

AMM is supported by National Institutes of Health [T32 AI007433]. The contents of this article are solely the responsibility of the authors and do not necessarily represent the official views of the National Institutes of Health.

\section{Disclosure}

The authors declare that they have no conflicts of interest.

\section{References}

1. Centers for Disease Control and Prevention (U.S.). Antibiotic Resistance Threats in the United States, 2019. Centers for Disease Control and Prevention (U.S.); 2019.

2. European Center for Disease Prevention and Control. Organization for Economic Cooperative Development. Antimicrobial resistance: tackling the burden in the European Union; 2019. Available from: https:// www.oecd.org/health/health-systems/AMR-Tackling-the-Burden-inthe-EU-OECD-ECDC-Briefing-Note-2019.pdf. Accessed December 21, 2021. 
3. Droz N, Hsia Y, Ellis S, Dramowski A, Sharland M, Basmaci R. Bacterial pathogens and resistance causing community acquired paediatric bloodstream infections in low- and middle-income countries: a systematic review and meta-analysis. Antimicrob Resist Infect Control. 2019;8(1):207. doi:10.1186/s13756-019-0673-5

4. Laxminarayan R, Duse A, Wattal C, et al. Antibiotic resistance- the need for global solutions. Lancet Infect Dis. 2013;13(12):1057-1098. doi:10.1016/S1473-3099(13)70318-9

5. International Organization for Migration, United Nations Department of Economic and Social Affairs. UN system task team on the post-2015 UN development agenda; May, 2012. Available from: https://www.un.org/millenniumgoals/pdf/Think\%20Pieces/13_migra tion.pdf. Accessed December 21, 2021.

6. Glaesser D, Kester J, Paulose H, Alizadeh A, Valentin B. Global travel patterns: an overview. J Travel Med. 2017;24(4). doi:10.1093/ $\mathrm{jtm} / \mathrm{tax} 007$

7. Tuite AR, Bhatia D, Moineddin R, Bogoch II, Watts AG, Khan K. Global trends in air travel: implications for connectivity and resilience to infectious disease threats. $J$ Travel Med. 2020;27(4):taaa070. doi: $10.1093 / \mathrm{jtm} / \mathrm{taaa} 070$

8. Edmond C. Global migration, by the numbers: who migrates, where they go and why. World Economic Forum; January 10, 2020. Available from: https://www.weforum.org/agenda/2020/01/iomglobal-migration-report-international-migrants-2020/. Accessed De cember 21, 2021.

9. Internal Displacement Monitoring Center. Internal Displacement. Available from: https://www.internal-displacement.org/internaldisplacement. Accessed December 21, 2021.

10. Castelli F, Sulis G. Migration and infectious diseases. Clin Microbiol Infect. 2017;23(5):283-289. doi:10.1016/j.cmi.2017.03.012

11. Kraemer MUG, Yang CH, Gutierrez B, et al. The effect of human mobility and control measures on the COVID-19 epidemic in China. Science. 2020;368(6490):493-497. doi:10.1126/science. abb4218

12. Barnett ED, MacPherson DW, Stauffer WM, et al. The visiting friends or relatives traveler in the 21st century: time for a new definition. J Travel Med. 2010;17(3):163-170. doi:10.1111/j.17088305.2010.00411.x

13. Ruppé E, Andremont A, Armand-Lefèvre L. Digestive tract colonization by multidrug-resistant Enterobacteriaceae in travellers: an update. Travel Med Infect Dis. 2018;21:28-35. doi:10.1016/j. tmaid.2017.11.007

14. Furuya-Kanamori L, Stone J, Yakob L, et al. Risk factors for acquisition of multidrug-resistant Enterobacterales among international travellers: a synthesis of cumulative evidence. $J$ Travel Med. 2020;27 (1):taz083. doi:10.1093/jtm/taz083

15. Grass JE, Kim S, Huang JY, et al. Quinolone nonsusceptibility among enteric pathogens isolated from international travelers - Foodborne Diseases Active Surveillance Network (FoodNet) and National Antimicrobial Monitoring System (NARMS), 10 United States sites, 2004-2014. PLoS One. 2019;14(12):e225800. doi:10.1371/ journal.pone. 0225800

16. Ruppé E, Armand-Lefèvre L, Estellat C, et al. High rate of acquisition but short duration of carriage of multidrug-resistant Enterobacteriaceae after travel to the tropics. Clin Infect Dis. 2015;61(4):593-600. doi:10.1093/cid/civ333

17. Arcilla MS, van Hattem JM, Haverkate MR, et al. Import and spread of extended-spectrum $\beta$-lactamase-producing Enterobacteriaceae by international travellers (COMBAT study): a prospective, multicentre cohort study. Lancet Infect Dis. 2017;17(1):78-85. doi:10.1016/ S1473-3099(16)30319-X

18. Worby CJ, Earl AM, Turbett SE, et al. Acquisition and long-term carriage of multidrug-resistant organisms in US international travelers. Open Forum Infect Dis. 2020;7(12):ofaa543. doi:10.1093/ ofid/ofaa543
19. Mellon G, Turbett SE, Worby C, et al. Acquisition of antibiotic-resistant bacteria by U.S. international travelers. $N$ Engl $J$ Med. 2020;382(14):1372-1374. doi:10.1056/NEJMc1912464

20. Voor In 'T Holt AF, Mourik K, Beishuizen B, et al. Acquisition of multidrug-resistant Enterobacterales during international travel: a systematic review of clinical and microbiological characteristics and meta-analyses of risk factors. Antimicrob Resist Infect Control. 2020;9(1):71. doi:10.1186/s13756-020-00733-6

21. Nurjadi D, Olalekan AO, Layer F, et al. Emergence of trimethoprim resistance gene dfrG in Staphylococcus aureus causing human infection and colonization in sub-Saharan Africa and its import to Europe. J Antimicrob Chemother. 2014;69(9):2361-2368. doi:10.1093/jac/ dku174

22. Kuhn KG, Hvass AK, Christiansen AH, Ethelberg S, Cowan SA. Sexual contact as risk factor for Campylobacter infection, Denmark. Emerg Infect Dis. 2021;27(4):1133-1140. doi:10.3201/eid270 4.202337

23. Allen H, Mitchell HD, Simms I, et al. Evidence for re-infection and persistent carriage of Shigella species in adult males reporting domestically acquired infection in England. Clin Microbiol Infect. 2021;27(1):126.e7-126.e13. doi:10.1016/j.cmi.2020.03.036

24. Hagmann SHF, Angelo KM, Huits R, et al. Epidemiological and clinical characteristics of international travelers with enteric fever and antibiotic resistance profiles of their isolates: a geosentinel analysis. Antimicrob Agents Chemother. 2020;64(11). doi:10.1128/ AAC.01084-20

25. Sridhar S, Turbett SE, Harris JB, LaRocque RC. Antimicrobialresistant bacteria in international travelers. Curr Opin Infect Dis. 2021;34(5):423-431. doi:10.1097/QCO.0000000000000751

26. Karami Z, Knoop BT, Dofferhoff ASM, et al. Few bacterial co-infections but frequent empiric antibiotic use in the early phase of hospitalized patients with COVID-19: results from a multicentre retrospective cohort study in The Netherlands. Infect Dis. 2021;53 (2):102-110. doi:10.1080/23744235.2020.1839672

27. Beović B, Doušak M, Ferreira-Coimbra $J$, et al. Antibiotic use in patients with COVID-19: a 'snapshot' Infectious Diseases International Research Initiative (ID-IRI) survey. $J$ Antimicrob Chemother. 2020;75(11):3386-3390. doi:10.1093/jac/dkaa326

28. Nellums LB, Thompson H, Holmes A, et al. Antimicrobial resistance among migrants in Europe: a systematic review and meta-analysis. Lancet Infect Dis. 2018;18(7):796-811. doi:10.1016/S1473-3099(18) 30219-6

29. Abbara A, Rawson TM, Karah N, et al. Antimicrobial resistance in the context of the Syrian conflict: drivers before and after the onset of conflict and key recommendations. Int J Infect Dis. 2018;73:1-6. doi:10.1016/j.ijid.2018.05.008

30. Karamya ZA, Youssef A, Adra A, et al. High rates of antimicrobial resistance among clinical isolates from microbiology laboratories in Syria. J Infect. 2021;82(2):e8-e10. doi:10.1016/j.jinf.2020.09.026

31. Reinheimer C, Kempf VAJ, Göttig S, et al. Multidrug-resistant organisms detected in refugee patients admitted to a University Hospital, Germany June-December 2015. Eurosurveillance. 2016;21(2). doi:10.2807/1560-7917.ES.2016.21.2.30110

32. Hargreaves S, Lönnroth K, Nellums LB, et al. Multidrug-resistant tuberculosis and migration to Europe. Clin Microbiol Infect. 2017;23 (3):141-146. doi:10.1016/j.cmi.2016.09.009

33. Walker TM, Merker M, Knoblauch AM, et al. A cluster of multidrug-resistant Mycobacterium tuberculosis among patients arriving in Europe from the Horn of Africa: a molecular epidemiological study. Lancet Infect Dis. 2018;18(4):431-440. doi:10.1016/ S1473-3099(18)30004-5

34. Githui WA, Hawken MP, Juma ES, et al. Surveillance of drug-resistant tuberculosis and molecular evaluation of transmission of resistant strains in refugee and non-refugee populations in North-Eastern Kenya. Int J Tuberc Lung Dis. 2000;4(10):947-955. 
35. Eimer J, Patimeteeporn C, Jensenius M, et al. Multidrug-resistant tuberculosis imported into low-incidence countries - a GeoSentinel analysis, 2008-2020. J Travel Med. 2021;28(6):taab069. doi:10.1093/jtm/taab069

36. Long R, Lau A, Egedahl ML, et al. Local transmission plays no important role in the occurrence of multidrug-resistant tuberculosis in immigrants to Canada: an In-depth epidemiologic analysis. J Infect Dis. 2021:jiab045. doi:10.1093/infdis/jiab045.

37. Thomas CM, Morkeberg OH, Walker PF, Stauffer WM. The cost of global connectivity: faster and more efficient spread of antimicrobial resistance by international travelers - a controversial commentary. Travel Med Infect Dis. 2021;41:102045. doi:10.1016/j. tmaid.2021.102045
38. $\mathrm{Hu} \mathrm{Y}$, Matsui Y, Riley LW. Risk factors for fecal carriage of drug-resistant Escherichia coli: a systematic review and meta-analysis. Antimicrob Resist Infect Control. 2020;9(1):31. doi:10.1186/s13756-020-0691-3

39. Wuerz TC, Kassim SS, Atkins KE. Acquisition of extended-spectrum beta-lactamase-producing Enterobacteriaceae (ESBL-PE) carriage after exposure to systemic antimicrobials during travel: systematic review and meta-analysis. Travel Med Infect Dis. 2020;37:101823. doi:10.1016/j.tmaid.2020.101823

40. International Organization for Migration. Key migration terms. Available from: https://www.iom.int/key-migration-terms. Accessed December 21, 2021

\section{Publish your work in this journal}

Infection and Drug Resistance is an international, peer-reviewed openaccess journal that focuses on the optimal treatment of infection (bacterial, fungal and viral) and the development and institution of preventive strategies to minimize the development and spread of resistance. The journal is specifically concerned with the epidemiology of antibiotic resistance and the mechanisms of resistance development and diffusion in both hospitals and the community. The manuscript management system is completely online and includes a very quick and fair peerreview system, which is all easy to use. Visit http://www.dovepress.com/ testimonials.php to read real quotes from published authors. 